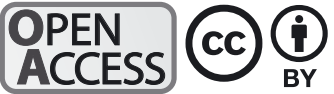

\section{Vertical salmon lice behaviour as a response to environmental conditions and its influence on regional dispersion in a fjord system}

\author{
Ingrid A. Johnsen ${ }^{1, *}$, Øyvind Fiksen ${ }^{2,3}$, Anne D. Sandvik ${ }^{1}$, Lars Asplin ${ }^{1}$ \\ ${ }^{1}$ Institute of Marine Research, PO Box 1870 Nordnes, 5817 Bergen, Norway \\ ${ }^{2}$ Department of Biology, University of Bergen and Hjort Centre for Marine Ecosystem Dynamics, Box 7803, 5020 Bergen, Norway
}

\begin{abstract}
The salmon louse Lepeophtheirus salmonis is a major parasite of salmon, and is able to travel between farms during its pelagic phases. We investigated the spatial dispersion of $L$. salmonis planktonic stages in the Hardangerfjord, Norway, using an individual-based model and a fjord circulation model. The models allowed us to investigate how assumptions about swimming responses to environmental cues affect vertical distribution, development and horizontal transport. The rules governing vertical distributions include passive particles remaining fixed at constant depths, but also prescribed responses of active particles to environmental cues such as ambient light level, salinity and temperature. Horizontal dispersion was affected by the vertical distribution scheme (rules) of the particles (each representing an individual planktonic-stage $L$. salmonis). When particles were held fixed in the surface layer, the horizontal dispersion and the area potentially affected by a source of lice decreased relative to the distribution that was predicted when lice had vertical migration behaviours. The simulations also showed that swimming triggered by both light and temperature may result in a diel migration pattern. If the particles sought out the warmest areas during juvenile stages, development to the infectious stage was reduced by up to $1 \mathrm{~d}$. Better information is required on the actual response of lice to a set of vertical environmental factors to improve predictions of lice dispersal in fjords.
\end{abstract}

KEY WORDS: Numerical model - Dispersion - Sea lice - Lepeophtheirus salmonis - Fjord · Circulation $\cdot$ Individual-based model $\cdot$ IBM $\cdot$ Vertical migration

\section{INTRODUCTION}

The salmon louse Lepeophtheirus salmonis is a natural parasite at temperate latitudes in the Northern Hemisphere (Pike \& Wadsworth 1999). With the introduction of aquaculture, the number of potential hosts for salmon louse has increased dramatically along the Norwegian coast. The parasite is now managed to secure the welfare of fish in the farms; however, treatments and controls are costly and affect profitability of the industry. The abundance of salmon lice along the Norwegian coast has increased due to farm activity, with negative effects on wild stocks of salmon and sea trout (Mo \& Heuch 1998, Finstad et al. 2000, Bjorn et al. 2001, Heuch et al.

${ }^{*}$ Corresponding author: ingrid.johnsen@imr.no
2009). The abundance of salmon lice on wild salmonid fish is monitored in selected areas along the Norwegian coast every spring. In recent years, the monitoring has been supplemented by numerical models, providing an alternative assessment of the abundance and distribution of salmon lice in whole fjord systems with a high resolution in time and space (Asplin et al. 2004, Brooks \& Stucchi 2006, Murray \& Gillibrand 2006, Gillibrand \& Willis 2007, Amundrud \& Murray 2009, Stucchi et al. 2011, Adams et al. 2012, Salama et al. 2013, Taranger et al. 2013).

To estimate the regional infection pressure of salmon lice using numerical dispersion models, we need to understand not only the flow of water in fjords and coastal regions, but also how salmon lice are adapted

(C) The authors 2014. Open Access under Creative Commons by Attribution Licence. Use, distribution and reproduction are unrestricted. Authors and original publication must be credited. 
to prevailing current systems and their behavioural swimming ability and responses to environmental gradients. It is recognized that planktonic organisms use circulation systems to increase their retention in favourable areas and to avoid drifting into areas with low survival or growth opportunities (Tapia \& Pineda 2007, Miller \& Morgan 2013). The key behavioural mechanism in achieving this is vertical positioning and migration (Fiksen et al. 2007, Vikebø et al. 2007). Previous studies of salmon louse have demonstrated that the parasite responds to external stimuli such as light and salinity gradients by vertical swimming (Bron et al. 1991, Heuch 1995, Heuch et al. 1995, Flamarique et al. 2000). However, these responses are observed when salmon lice are held under idealized conditions with no turbulence and only a single stimulus. How to use these findings in a numerical model and define the response of simulated salmon lice to multiple environmental cues at the same time is not straightforward.

Using numerical modelling, we tested the sensitivity of simulated lice distribution patterns to a set of vertical swimming responses in a Norwegian fjord. We focus on lice responses to gradients in water salinity, light and temperature. These parameters often take vertical gradients in the upper $\sim 50 \mathrm{~m}$, where the salmon lice are assumed to reside. While responses to salinity and light have been observed in laboratory experiments, temperature is known to affect lice growth and development (Johnson \& Albright 1991). In addition to simulations that included salmon lice behaviour such as swimming response triggered by salinity and light, we conducted an experimental simulation where salmon lice prior to the infectious stage were given the ability to sense and migrate towards warmer water. It might be beneficial for pre-infectious salmon lice to reside in the warmest waters to reduce stage duration to the infectious stage and thereby reduce its risk of mortality. Whether salmon lice actually respond to temperature gradients in this way is unknown. The rules were not implemented to produce realistic distributions, but rather to demonstrate the logical consequence of a rigid response pattern to some environmental cues. These rules may lead to maladaptive distributions, but it illustrates the challenge involved in implementing sound or experimentally observed behavioural responses in these models. The numerical experiments were conducted to see if salmon lice are able to affect their development time to the infectious copepodite stage by vertical positioning, and how such behaviour affects horizontal drift.

\section{MATERIALS AND METHODS}

\section{Study area}

The Hardangerfjord area is a complex fjord system consisting of several fjords, narrows and bays (Fig. 1). Located on the west coast of Norway, the fjord system is connected to coastal water through several fjord mouths and inlets. Stratification and circulation results from forcing mechanisms such as freshwater input, tides, wind and stratification outside the fjord mouth (Gill 1982, Farmer \& Freeland 1983, Stigebrandt 2012). Depending on the forcing mechanisms and topography, both stratification and currents fluctuate in time and space (Stigebrandt 2012, Asplin et al. 2014). In the Hardangerfjord, the wind is shown to generate strong current episodes of 1-2 d duration in the upper $\sim 10 \mathrm{~m}$ (Asplin et al. 2014). A brackish layer generates shallow $(\sim 5 \mathrm{~m})$ outflows in periods with strong stratification close to the surface (Asplin et al. 2014). Internal pressure forces between the water inside the fjord and the external coastal water result in an effective water exchange with velocities of $0.1-0.3 \mathrm{~m} \mathrm{~s}^{-1}$ lasting for 5-10 d. Pulses occur approximately every month in the upper $\sim 50 \mathrm{~m}$, though not always apparent in the top $5 \mathrm{~m}$ because they are masked by the additional flow components from the wind and the freshwater discharge (Asplin et al. 2014). The tidally driven current is found to be modest at $\sim 0.05 \mathrm{~m} \mathrm{~s}^{-1}$ in deep parts of the Hardangerfjord (Asplin et al. 2014).

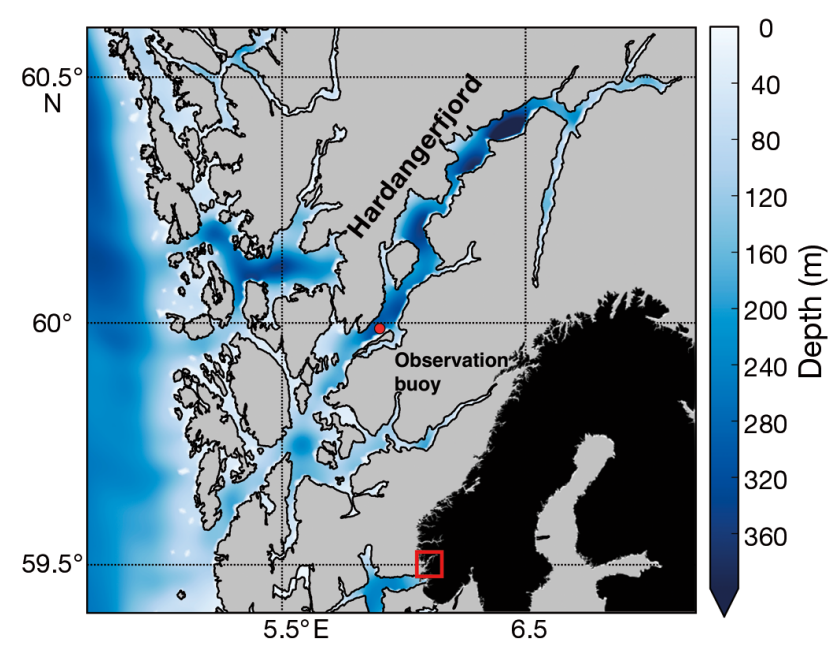

Fig. 1. Study area in the Hardangerfjord, Norway. The position of the observational buoy where we collected current data for model validation is indicated (•). Inset: Scandinavian Peninsula (study area marked with $\square$ ) 


\section{The fjord model}

The numerical circulation model we used is an implementation of the Regional Ocean Model System, NorKyst800 (Shchepetkin \& McWilliams 2005, Albretsen 2011; www.myroms.org). Freshwater input from about 100 rivers was put into the model using results from a data-driven hydrological model developed by the Norwegian Water Resources and Energy Directorate (NVE) (Petterson 2008). Results from the Weather Research and Forecasting (WRF) mesoscale atmosphere model (www.wrf-model.org) were used to provide temperature, air pressure, moisture, precipitation and wind forcing at a $3 \mathrm{~km}$ grid resolution, every 3rd hour. Cloud cover was taken from the ERA-Interim reanalysis every 6th hour. Vertically, the model has 35 terrain-following coordinate levels with the highest vertical resolution in the upper $30 \mathrm{~m}$. The internal time step of solving the equations of conservation of momentum, temperature and salinity was $10 \mathrm{~s}$, and results were stored hourly.

The circulation model was run for the year 2009; in addition, the model was downscaled for the Hardangerfjord area with a horizontal resolution of $200 \times$ $200 \mathrm{~m}$ for the period 1 April to 24 August. The time limitations of the downscaling were set as a combination of data storage limitations, and the downscaling originally was done in connection with management studies focusing on the time period of seaward migration of salmon smolt and fjord feeding of sea trout. In the fine-resolution model run, NorKyst800 provided initial field and hourly updated external boundary conditions, and the atmospheric boundary conditions from WRF were downscaled to $1 \mathrm{~km}$ resolution.

Measurements from a buoy placed at a single location in the fjord (Fig. 1 ; $\left.59^{\circ} 59.292^{\prime} \mathrm{N}, 5^{\circ} 54.121^{\prime} \mathrm{E}\right)$ made it possible to compare simulated currents at $11 \mathrm{~m}$ depth with the actual currents from 8 May to 8 July 2009. Along-fjord components of the velocity were calculated, where positive values are currents directed into the fjord (Fig. 2). Simulated currents (green and red lines in Fig. 2) were stored as hourly averaged values, while the sampling interval at the buoy was 10 min (red line in Fig. 2). Both model and measured currents were resampled to hourly values and smoothed with a 4th-order Butterworth low-pass filter with a cut-off period of $24 \mathrm{~h}$. The mean $( \pm \mathrm{SD})$ measured current speed at $11 \mathrm{~m}$ was $0.14 \pm 0.10 \mathrm{~m} \mathrm{~s}^{-1}$. The corresponding modelled values (mean $\pm \mathrm{SD}$ ) from the $200 \mathrm{~m}$ and $800 \mathrm{~m}$ resolution models were $0.13 \pm 0.10 \mathrm{~m} \mathrm{~s}^{-1}$ and $0.09 \pm 0.06 \mathrm{~m} \mathrm{~s}^{-1}$ respectively. When decomposing the speed to along-fjord currents directed into or out of the fjord, we observed that the currents directed into the fjord were underestimated by the $200 \mathrm{~m}$ resolved model. The $800 \mathrm{~m}$ resolved model underestimated the peak velocities (Fig. 2: green line). This was expected, since the energy available for generating currents was averaged over a large area. By increasing the model resolution to $200 \mathrm{~m}$ (Fig. 2: blue line), we were able to increase the magnitude of the currents at the observation location. The comparison otherwise showed a good correlation between observations and simulations, and we believe that the models were able to realistically recapture the actual currents (Fig. 2).

\section{Biological model outline}

Salmon lice in planktonic stages were simulated using an individual-based model, where particles (representing planktonic-stage L. salmonis) were released in the fjord and advected based on the current from the circulation model using a 4th-order Runge-Kutta scheme solving the Lagrangian equation of motion. Non-reflecting boundaries were used along land, simply holding the particle at its position if its trajectory was directed onto land. The surface acts as a reflecting border, while no depth limit was

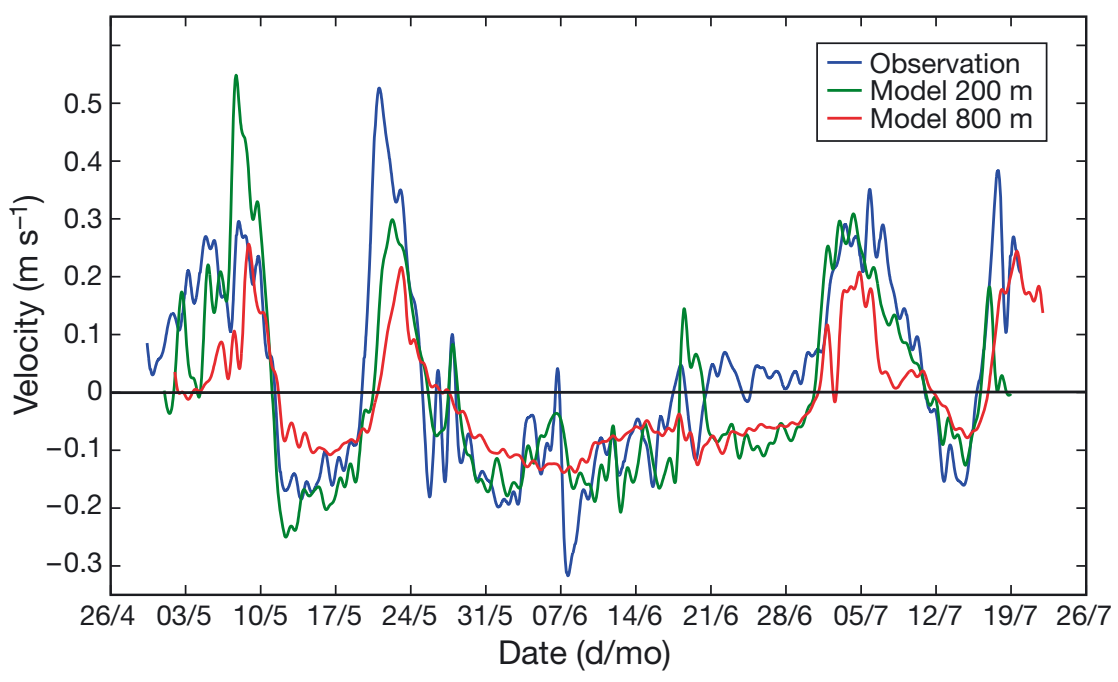

Fig. 2. Along-fjord current at $11 \mathrm{~m}$ depth from an observational buoy in the Hardangerfjord (blue line) and from the corresponding position in the $200 \mathrm{~m}$ (green line) and $800 \mathrm{~m}$ (red line) resolution numerical models. Positive values are currents directed towards the head of the fjord 
set for the particles but the sea floor. Particles entering the offshore grid boundary were excluded from further calculations.

The particles were given temperature-dependent development, defining the salmon lice stage transitions, and also the ability to migrate vertically in response to temperature, light and salinity. Simulations were performed assuming salmon lice remain at fixed depth and assuming active habitat selection depending on the surrounding light, salinity and temperature conditions. Fjord circulation provided the environmental conditions: salinity and temperature. Mortality and diffusion within the model grid together with light and behavioural cues were defined as follows.

\section{Diffusion}

Particles were given a random movement component both vertically and horizontally at each time increment. This was done to represent turbulence on a sub-grid scale and fluctuating swimming motion by the salmon louse itself. Random velocity $\left(\delta w_{R}\right)$ was given by the following expression:

$$
\delta w_{R}=R \sqrt{\frac{2 D}{\delta t}}
$$

Here, $\delta t$ is the discrete time step, $R$ is a random number normally distributed around 0 , and $D$ is the diffusion coefficient, set to $0.02 \mathrm{~m}^{2} \mathrm{~s}^{-1}$ horizontally and $10^{-3} \mathrm{~m}^{2} \mathrm{~s}^{-1}$ vertically. This corresponds to a horizontal and vertical random velocity within $\pm 1.5 \mathrm{~cm}$ $\mathrm{s}^{-1}$ and $0.3 \mathrm{~cm} \mathrm{~s}^{-1}$, respectively. A vertical diffusion coefficient of $D=10^{-3} \mathrm{~m}^{2} \mathrm{~s}^{-1}$ corresponds to the turbulent mixing observed in the open ocean at wind velocities of $\sim 3 \mathrm{~m} \mathrm{~s}^{-1}$ (Sundby 1983).

\section{Age, development and mortality}

We set the simulated salmon lice to enter the infectious copepodite stage at 50 degree-days. Development was calculated for each particle, where the degree-day simply is the integrated temperature over time. The first 2 stages, nauplius I and II, require about 30 to 50 degree-days to complete (Stien et al. 2005), while the third and infectious copepodite stage lasts approximately another 100 degree-days (Asplin et al. 2011). In the following simulations and illustrations, the infectious copepodite stage is assumed to have a lifespan between 50 and 150 degree-days. All salmon lice past 150 degree-days were assumed to be dead from senescence or starvation.
In all simulations, independent of environment and stage, the immediate mortality rate per day was set fixed to $0.17 \mathrm{~d}^{-1}$, as estimated by Stien et al. (2005). This corresponds reasonably well with the general size-dependent pattern of mortality rates for pelagic invertebrates (Peterson \& Wroblewski 1984, McGurk 1986). In nature, mortality of salmon lice is probably influenced by several factors, such as hatching, predation and energy depletion due to swimming and respiration, but these are very much known unknowns. Swimming activity might affect mortality both through energy spent on the swimming and as the salmon louse makes itself more exposed to predation from ambush invertebrate predators through hydromechanical signals (Kiørboe 2008). As we have limited knowledge of predation and swimming costs, we kept mortality at a constant rate. In order to evaluate the swimming cost, the total swimming distance was counted for all simulated salmon lice.

Light and sensing of irradiance

The diel light cycle at the surface was calculated from Skartveit \& Olseth (1988). The study area is located at $60^{\circ} \mathrm{N}$, where the level of irradiance to the surface $H_{0}(t, d)$ at time $(t)$ and day of the year $(d)$ were set to $1500 \mu \mathrm{mol}$ photons $\mathrm{s}^{-1} \mathrm{~m}^{-2}$ at midday and $1.15 \times 10^{-5} \mu \mathrm{mol}$ photons $\mathrm{s}^{-1} \mathrm{~m}^{-2}$ at twilight. Simulations were conducted for March and May and the daylight period was increasing. The level of light $H(z, t, d)$ was decreasing exponentially with depth $(z)$ according to:

$$
H(z, t, d)=H_{0}(t, d) \times \mathrm{e}^{-k z}
$$

The attenuation coefficient $k$ was set constant in time and space to $0.2 \mathrm{~m}^{-1}$. The attenuation coefficient is known to correlate with salinity, oxygen and chlorophyll (Aksnes et al. 2009), but for the present investigation we found our simpler formulation to suffice.

The simulated salmon lice were given the ability to react to irradiance above a critical level of $0.39 \mu \mathrm{mol}$ photons $\mathrm{s}^{-1} \mathrm{~m}^{-2}$ for nauplii and $2.06 \times$ $10^{-5} \mu \mathrm{mol}$ photons $\mathrm{s}^{-1} \mathrm{~m}^{-2}$ for copepodites (Flamarique et al. 2000). This was done to mimic findings in lab experiments, where salmon lice are shown to swim towards the light (Bron et al. 1993). Observations of vertical movement of lice in a water column support this observation, with lice migrating towards the surface during the day and sinking down at night (Heuch et al. 1995). When exposed to light exceeding the critical threshold, we assumed the lice react by swimming towards the surface. As the salmon lice showed reaction 
to light with lower intensities when entering the copepodite stage, the nauplii were triggered by light in a more limited area close to the surface than the copepodites. With $k=0.2 \mathrm{~m}^{-1}$, the nauplii and copepodites did not react to light at any time of the day below 40 and $90 \mathrm{~m}$ depth, respectively (Fig. 3).

\section{Sensing of salinity}

Our behaviourally responsive salmon lice were given the ability to sense the salinity of the ambient water. With exposure to water with salinity $<20$, we assumed there would be a downward swimming response to escape the low-salinity water. Salmon lice avoid low-salinity water in laboratory experiments (Heuch 1995, Bricknell et al. 2006). Different results have been published on the lower salinity threshold for salmon lice, and they are found in lower salinity water in a multiple-step salinity gradient than in a single-step gradient (Johnsen \& Albright 1991, Heuch 1995, Bricknell et al. 2006). Due to the proximity of major rivers and various mixing forces, the low-salinity layer close to the surface was most predominant in the inner part of the Hardangerfjord.

\section{Sensing of temperature}

In one model experiment, we assumed the salmon louse to be capable of sensing temperature just above and below its current position during a time step of $180 \mathrm{~s}$ before deciding to swim up or down or to stay at its present depth. Lice were given the abil-

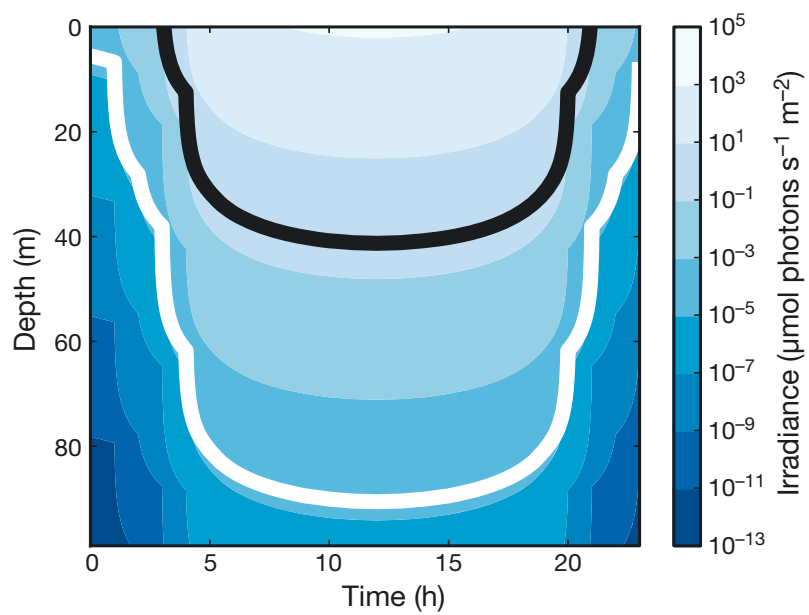

Fig. 3. Simulated diurnal irradiance for the date 1 May at $60^{\circ} \mathrm{N}$. Thick solid lines represent the assumed light-detection threshold for Lepeophtheirus salmonis copepodites (white line) and nauplii (black line). Time: hours past midnight 1st May 00:00:00 UTC ity to swim to the depth with the highest temperature to minimize development time and maximize survival to the infectious stage. Whether this resulted in upward or downwards swimming was dependent on the vertical temperature gradient at the time. Seasonal differences in vertical temperature profiles were apparent in the model results, with warmer and less saline water towards the surface in the spring but colder water towards the surface in the winter (Fig. 4). We have no observations indicating such a response of salmon louse nauplii, but implemented the behaviour to investigate if the salmon lice theoretically can improve survival to copepodite stage assuming constant mortality in time and space.

\section{Vertical swimming ability}

All salmon lice particles with the ability to respond to environmental cues were given an absolute swimming speed of $0.5 \mathrm{~mm} \mathrm{~s}^{-1}$. This is less than the peak velocities observed in laboratory experiments (Heuch \& Karlsen 1997), and is about 1 body length $\mathrm{s}^{-1}$ of nauplii I, and represents a reasonable sustained swimming speed (Kiørboe et al. 2010). Vertical swimming was only directed up towards the surface when triggered by light and down when triggered by low salinities, but could be directed both up and down for temperature-controlled salmon lice. As salmon lice are found to be heavier than seawater (Bricknell et al. 2006), only upward swimming has been considered to be energy-consuming. In the absence of ex-
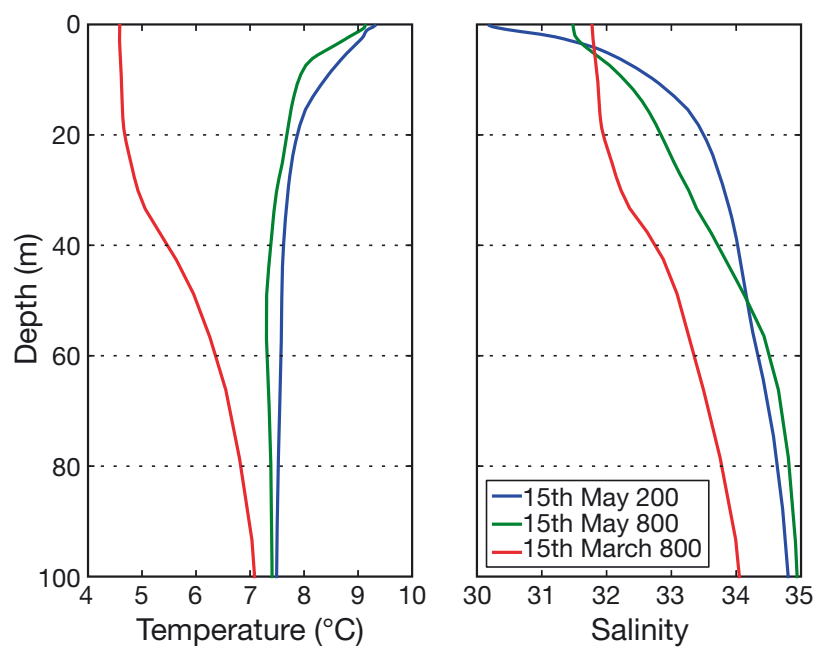

Fig. 4. Simulated (a) temperature and (b) salinity profiles at the outer part of the Hardangerfjord. Diurnal mean from 15 March and 15 May from the model NorKyst800 (green and red lines; $800 \mathrm{~m}$ resolution) and the fjord model (blue line; $200 \mathrm{~m}$ resolution) 
ternal stimuli, the salmon lice did not swim actively, nor sink or float, but were only being mixed by the turbulent forces.

\section{Experimental setup}

We performed 2 types of experiments, one with vertically passive particles at fixed depths and one with certain environmental cues determining lice vertical positioning. Newly hatched salmon lice particles were released in the model before being advected by the currents from the fjord model. The model stored the particles' horizontal and vertical position and the temperature and salinity of the ambient grid cell every hour. Note that we switch between the terms 'salmon lice' (or just 'lice'), 'nauplii', 'copepodites' and 'particles' here, all referring to the particles with salmon lice properties dispersed by the flow field.

In Expt 1, a single release of passive particles was held at fixed depths to illustrate changes in horizontal transport at different depths.

Expt 2 consisted of 3 simulations where particles were continuously released every hour, with the following behavioural responses:

- Simulation 'Surf': the particles were released and held fixed in the surface layer of thickness $0.3-0.6 \mathrm{~m}$. This was done just as the surface simulation in Expt 1, but with a continuous release of particles

- Simulation 'Light': all particles migrated vertically. They swam upwards when exposed to light exceeding a critical limit, and downwards when exposed to low salinity $(<20)$. If exposed to both light and low salinity, downward sinking dominates. In addition, the particles were mixed by turbulent forces

- Simulation 'Temp': particles at the copepodite stage migrate vertically as in experiment 'Light', but during the nauplii stages the lice particles selected depth to achieve the highest ambient temperature and minimize development time without any reaction to light or salinity

The stage-duration of salmon lice depended on integrated temperature exposure, and consequently the cumulative survival probability to adulthood differed among stages and particles. The vertical distribution of simulated salmon lice was continuously shifting in time as the environmental conditions perceived by the individual salmon louse changed. Both horizontal and vertical distributions are presented as accumulated distributions, integrated in time throughout the simulation periods.

\section{Initialization}

In Expt 1, 10 particles were released at 2 sites in the Hardangerfjord at 0, 10, 20 and $30 \mathrm{~m}$ depths and followed for $1 \mathrm{mo}$. The release depths down to $30 \mathrm{~m}$ were chosen because fish farms in the Hardangerfjord normally are $30 \mathrm{~m}$ deep. In Expt 2, new particles were released hourly at a single location throughout the simulation. To obtain the same number of lice in the simulations, 70 particles were released at the surface in simulation 'Surf', while 10 particles were released at every fifth metre from the surface down to $30 \mathrm{~m}$ depth for particles having light- and temperature-controlled behaviour. Age increments, survival, turbulent mixing and vertical swimming decisions were made at an internal time step of $180 \mathrm{~s}$. Expt 2 was performed for March and May 2009, each with different vertical gradients of light, salinity and temperature due to the different seasons. A highly resolved current field from the fjord model was not available for March, hence this flow field was produced by NorKyst800, with a coarser horizontal resolution. The May simulation was done for both current fields to evaluate the differences between the 2 grid resolutions.

The simulations were conducted to reveal effects of alternative hypotheses for active vertical positioning by salmon lice on their horizontal dispersion. Horizontal position and developmental stage of each single louse were followed to test if the vertical positioning of the salmon louse, given a constant mortality rate, may affect lice stage duration and survival to the infectious stage. In both horizontal and vertically aggregated distribution plots, all salmon lice particles were weighted by their probability of survival.

\section{RESULTS}

\section{Horizontal distribution}

In Expt 1, the particle transportation differed both with the residing depth and the release position (Fig. 5). The particles fixed at the surface were those transported the shortest distance from their release positions. This was a common feature for both release positions. From the inner position, the mean transportation during 1 mo was $40 \mathrm{~km}$. The shortest dispersal distances were found for particles fixed at the surface. The difference with residing depth was less than for the ones released at the outer position. The particles released at the outer position at 0 and $10 \mathrm{~m}$ depths were advected the least distance from their re- 

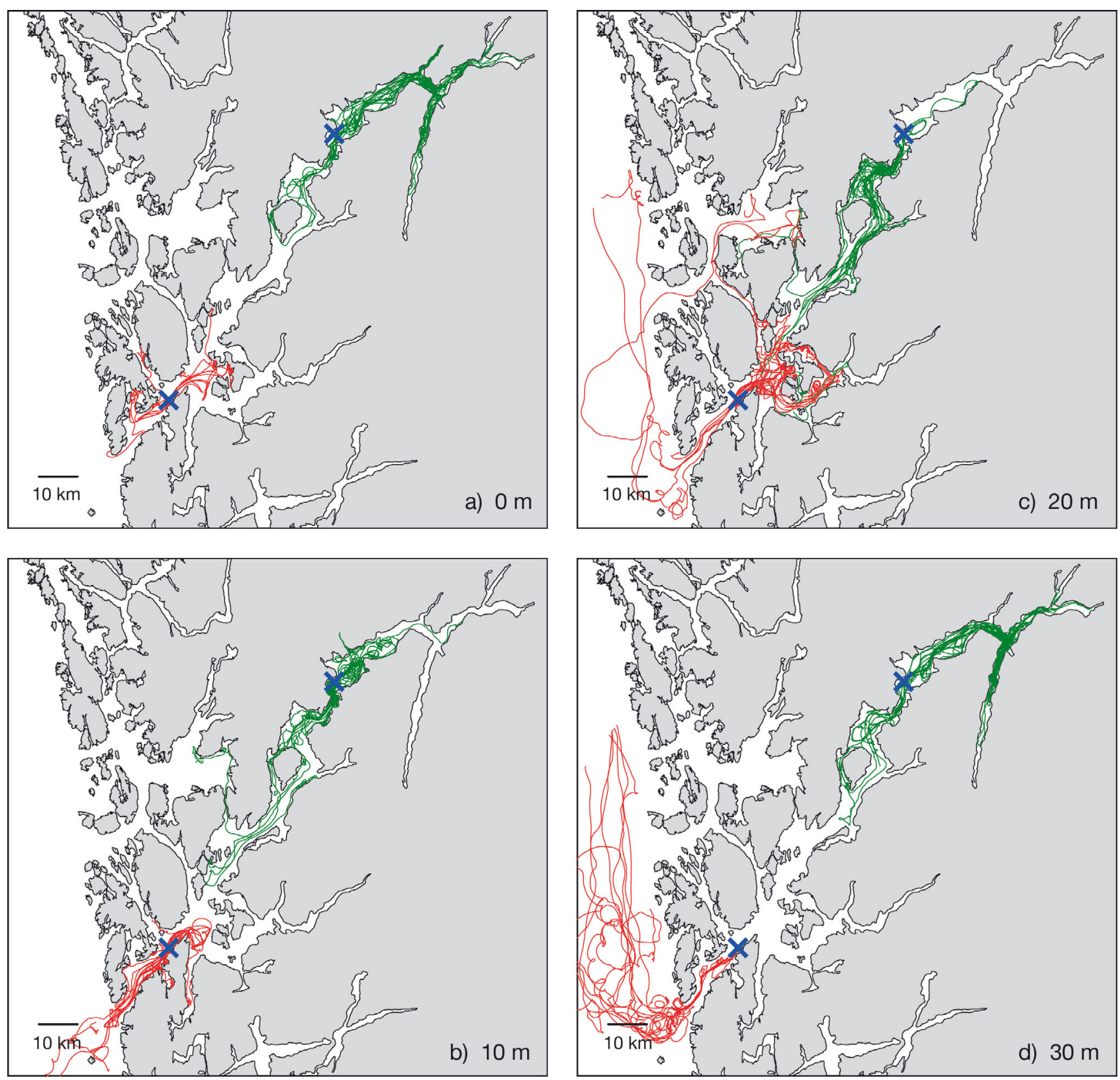

Fig. 5. Trajectories of 10 particles (simulated Lepeophtheirus salmonis in planktonic stages) released and fixed at (a) 0 m, (b) $10 \mathrm{~m}$, (c) $20 \mathrm{~m}$ and (d) $30 \mathrm{~m}$ depths at 2 positions in the Hardangerfjord. The simulated period is 1-30 May 2009, based on current fields from the $200 \mathrm{~m}$ resolution fjord model. Blue crosses: release locations of particles; red trajectories: particles released at the outer position; green trajectories: particles released at the inner position

lease position, with a mean travel distance of 15 and $26 \mathrm{~km}$, respectively (Fig. 5a,b). The relatively short transport of the particles was due to wind-driven cross-fjord currents close to the surface accumulating the particles along the shoreline. Particles fixed at the same depths released at the inner position were not forced towards land to the same extent. The trajectories of particles released from the outer position at 20 $m$ depth covered a large area in the fjord, with a mean transportation of $32 \mathrm{~km}$ from the source (Fig. 5c). Par- ticles at $30 \mathrm{~m}$ depth were transported effectively out of the fjord and to the north along the coast, resulting in the greatest transports, with a mean value of $57 \mathrm{~km}$ from their release position (Fig. 5d). Simulations were repeated for a release of 20,30,50 and 100 particles at every depth, as a sensitivity test. The simulations showed different particle trajectories due to stochasticity in the dispersal. The variance was largest for the particles at the surface, decreasing for particles at deeper depths. Neither the mean transportation of 
particles during 1 mo nor the standard deviation between the transported distances decreased by increasing the number of particles released.

To test the effects of the variability of the current, which we know vary in time and space (Asplin et al. 2014), we performed the same experiment with particle release on 1 June and 1 July 2009. While the particles released on 1 June were transported out of the fjord at all depths, the particles released on 1 July were rapidly transported into the fjord and with a greater transport speed at $10 \mathrm{~m}$ depth than at the surface. For all experiments, the variance of total transported distance and the direction for the 1 mo simulations decreased with increasing depths.

In Expt 2, the different vertical distributions due to individual behavioural cues caused different horizontal distribution patterns. New salmon lice were released hourly and transported from the source by ocean currents. The horizontal distribution plots (Figs. $6 \&$ 7) show the aggregated density of salmon lice copepodites during the simulation. A retention where $75 \%$ of the infectious salmon lice copepodites were found within $22-37 \mathrm{~km}$ from their release position was found in all simulations, except for temperature-controlled salmon lice during March, where $75 \%$ were found only $16 \mathrm{~km}$ from their source. Some salmon lice were rapidly transported out of the fjord, where they continued to drift northwards with the prevailing currents.

The simulations during May were performed on both 200 and $800 \mathrm{~m}$ resolved current fields. The horizontal dispersion of salmon lice was not identical for the 2 simulations, since the 2 current models differed in both resolution and wind forcing (Fig. 7). Simulations using both current fields resulted in similar affected areas, but the finer-resolved model resulted in larger differences between the surface and behavioural simulations, caused by a greater vertical current shear in the $200 \mathrm{~m}$ compared to the $800 \mathrm{~m}$ model. All simulations were also performed for release at the inner position in Expt 1. Here, the $800 \mathrm{~m}$ resolved model dispersed salmon lice significantly less than the $200 \mathrm{~m}$ model, indicating that the low-resolution flow field was inadequate to simulate dispersion at the narrower inner parts of the fjord.

The salmon lice reached the infectious stage about a week after they were hatched, and therefore the largest densities of copepodites were typically not found near the release position. Independent of month, the total dispersal area was smallest for lice fixed at the surface and largest for the temperaturecontrolled simulation. Particles fixed at or residing mainly close to the surface were found most densely

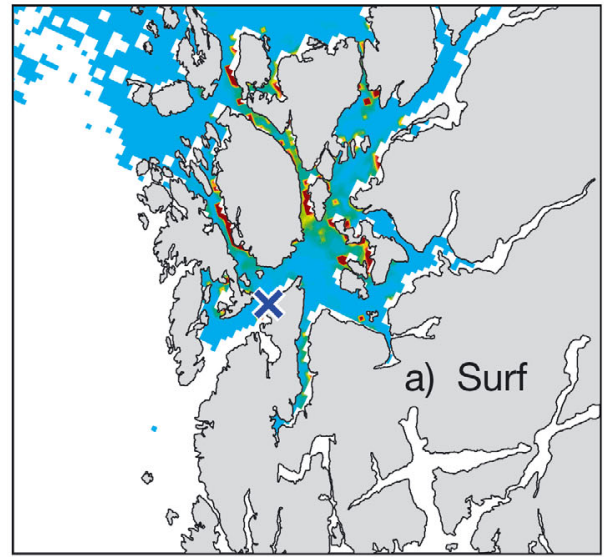

0.24

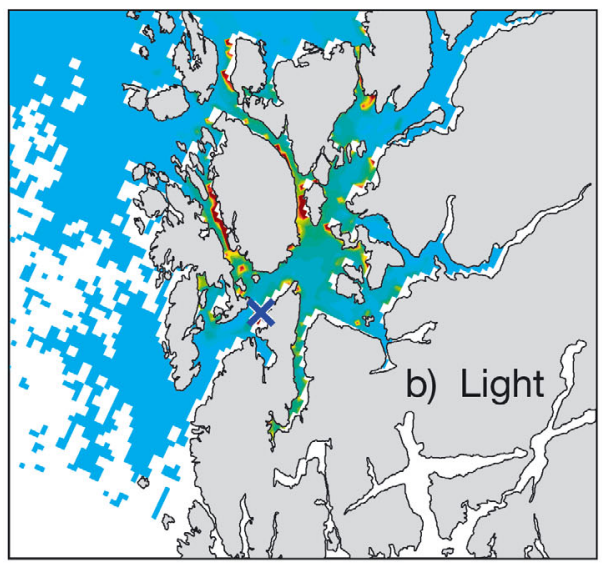

0.21

0.18

0.15

0.12

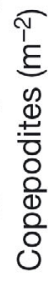

0.09

0.06

0.03

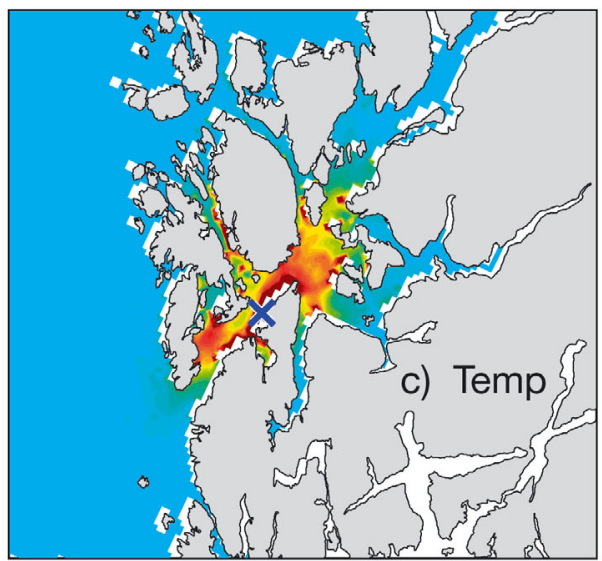

Fig. 6. Simulated horizontal dispersion of Lepeophtheirus salmonis in the Hardangerfjord during 1-31 March 2009 based on current fields from the model NorKyst800. Plots show vertical and time-integrated distribution of copepodite particles with different behaviours: (a) fixed at the surface (Surf), (b) vertical migration controlled by light and salinity (Light), and (c) temperature-controlled vertical migration (Temp). Blue crosses indicate release locations of particles. Particles were counted in grid cells of $800 \mathrm{~m} \times 800 \mathrm{~m}$, and divided by the cell area 

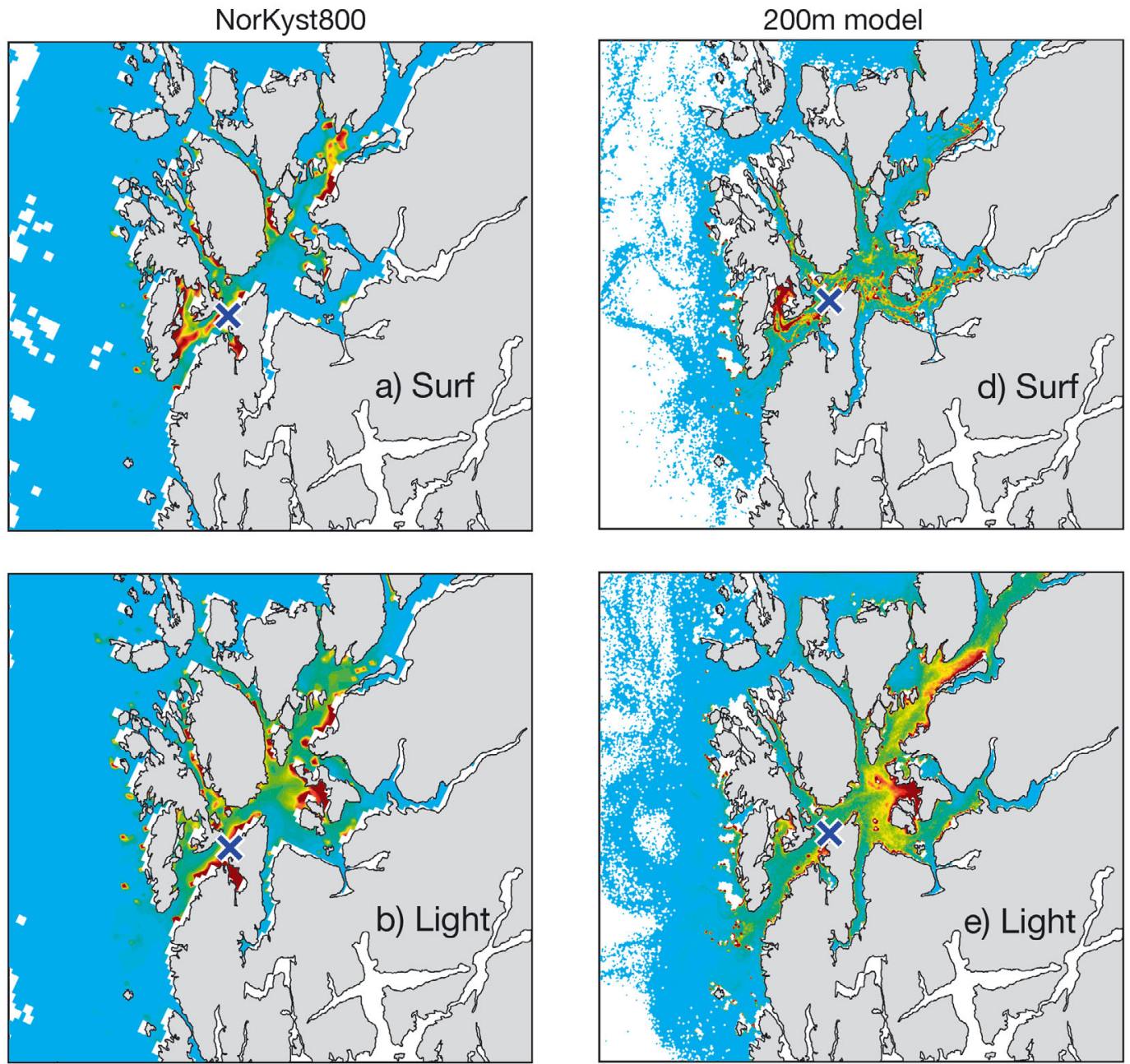

0.24

0.21

0.18
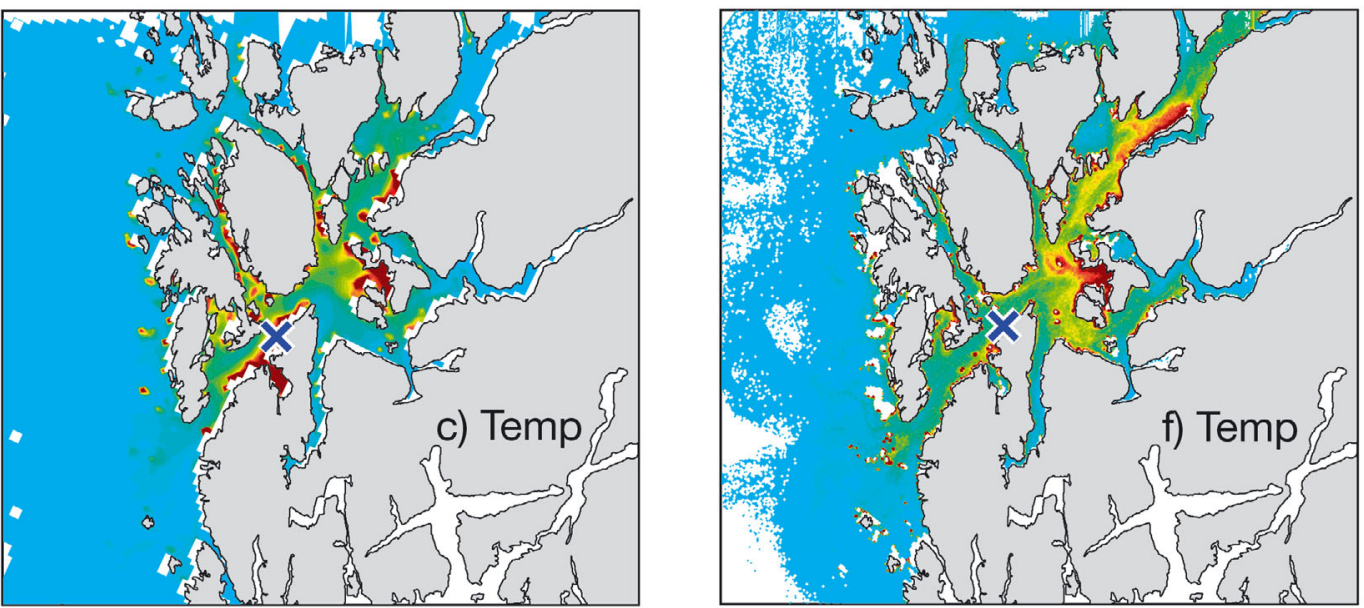

Fig. 7. Simulated horizontal dispersion of Lepeophtheirus salmonis in the Hardangerfjord during 1-31 May 2009 based on current fields from $(\mathrm{a}-\mathrm{c})$ the model NorKyst800 and $(\mathrm{d}-\mathrm{f})$ the $200 \mathrm{~m}$ resolution fjord model. Plots show vertical and time-integrated distribution of copepodite particles with different behaviours: (a,d) fixed at the surface (Surf), (b,e) vertical migration controlled by light and salinity (Light), and (c,f) temperature-controlled vertical migration (Temp). Blue crosses indicate release locations of particles. Particles were counted in grid cells of $800 \times 800 \mathrm{~m}$ (lefthand panels) and $200 \times 200 \mathrm{~m}$ (righthand panels), 
in patches along the shoreline within $40 \mathrm{~km}$ from their source during the infectious copepodite stage (Figs. $6 \& 7$ ). The closer to the surface the lice resided, the more they aggregated along the shoreline. The aggregation differences between the surface-, light- and temperature-controlled simulations were more evident in the simulation based on the $200 \mathrm{~m}$ resolved current field (Fig. $7 \mathrm{~d}-\mathrm{f}$ ). Here, $75 \%$ of the infectious copepodites with vertical behaviour determined by light and temperature both resided within $13 \%$ of the total influenced area. And $75 \%$ of copepodites fixed at the surface were accumulated within only $3 \%$ of the influenced area.

The patchiness was more evident in the $800 \mathrm{~m}$ simulation than in the better-resolved $200 \mathrm{~m}$ simulation (Fig. 7). Different horizontal diffusion coefficients were tested, but even with a 16-times larger coefficient $\left(D=0.32 \mathrm{~m}^{2} \mathrm{~s}^{-1}\right)$, the patchiness was only slightly less, but did not become visually apparent.

The temperature-controlled nauplii migrated deep into warmer waters during the March simulations, leading to a different distribution than for the salmon lice fixed at the surface or those migrating towards the light. In the temperature-controlled simulation, high densities of infectious copepodites were found close to the source, and decreased with distance from the release position. The salmon lice copepodites were more dispersed and the accumulation of lice in small patches was less apparent than for the other 2 simulations (Fig. 6).

\section{Vertical distribution}

The moderate vertical turbulent forces in the system did not prevent particles from controlling their vertical position by vertical swimming. A diurnal migration in the upper $10 \mathrm{~m}$ emerged for all lightcontrolled salmon lice during the nauplii stages (Fig. 8) and for copepodites during March (Fig. 9). Due to seasonal changes in irradiance, the light-controlled salmon lice came closer to the surface in May, with smaller migration amplitude than in March (Figs. 8 \& 10). During the copepodite stage, the lightcontrolled salmon lice were exposed to light exceeding the critical limit for up to $16 \mathrm{~h} \mathrm{~d}^{-1}$. As they responded by upward swimming most of the day, the light-controlled copepodites showed no diurnal migration during May (Fig. 9).

The temperature-controlled behaviour led to a different vertical distribution in March compared to May. This was a result of the seasonally changing temperature shears. As the temperatures were high-
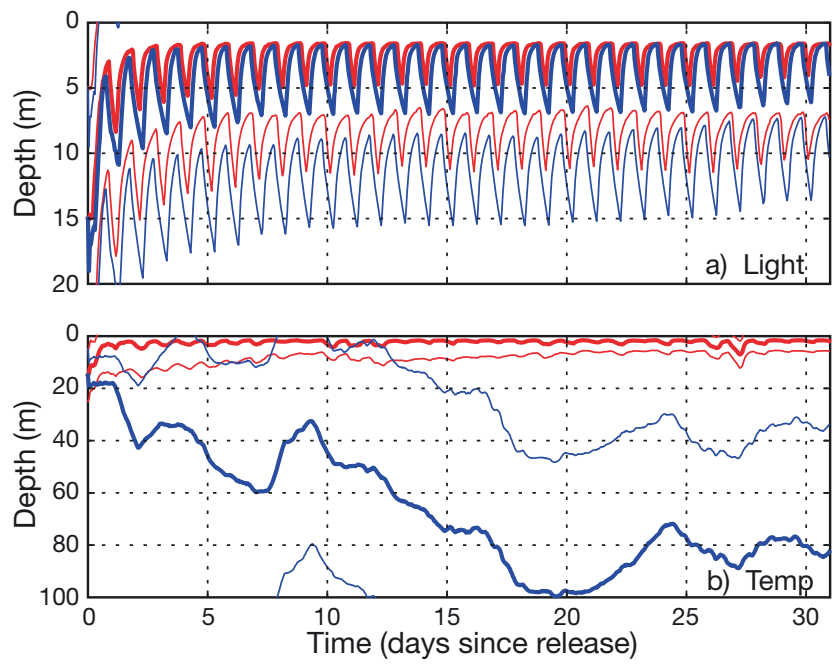

Fig. 8. Median depth (thick lines) \pm 1 SD (thin lines) during the nauplii stages in (a) light- and (b) temperature-controlled simulated Lepeophtheirus salmonis during the simulation periods March (blue lines) and May (red lines) 2009 based on current fields from the model NorKyst800
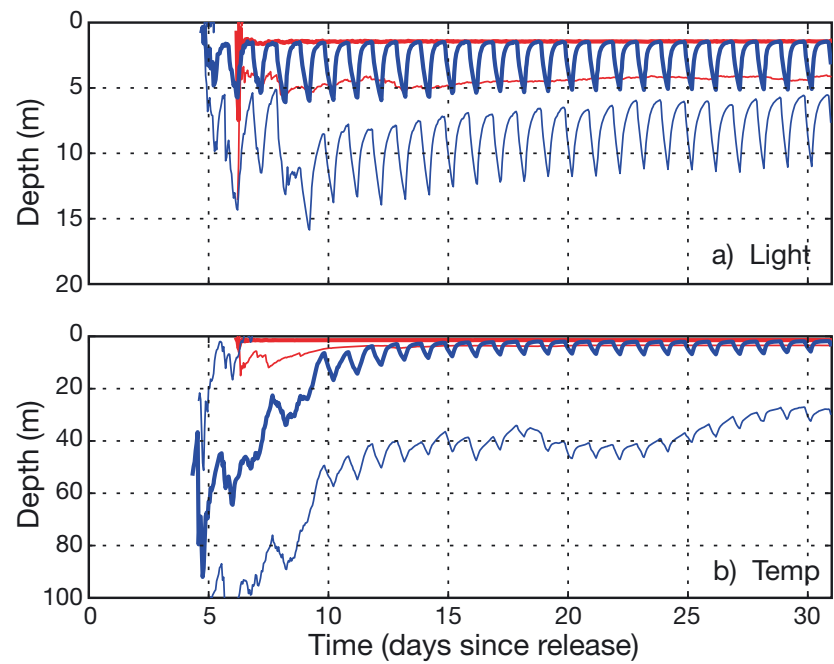

Fig. 9. Median depth (thick lines) \pm 1 SD (thin lines) during the copepodite stages of simulated Lepeophtheirus salmonis during the simulation periods March (blue lines) and May (red lines) 2009 based on currents field from the model NorKyst800. All copepodites were swimming vertically depending on ambient light. (a) 'Light' (light-controlled) and (b) 'Temp' (temperature-controlled) denote the vertical behaviour during the naupliar stages

est close to the surface in May, the temperaturecontrolled salmon lice swam towards the surface, resulting in a vertical distribution similar to the lightcontrolled nauplii (Fig. 8). Temperature-controlled nauplii close to the surface in May migrate diurnally over 0.5-2 m (Fig. 8b). The nauplii seeking the highest ambient temperature got quite a different vertical distribution in March. Under winter temperature profiles (Fig. 4), the nauplii swam deep down, with a median 


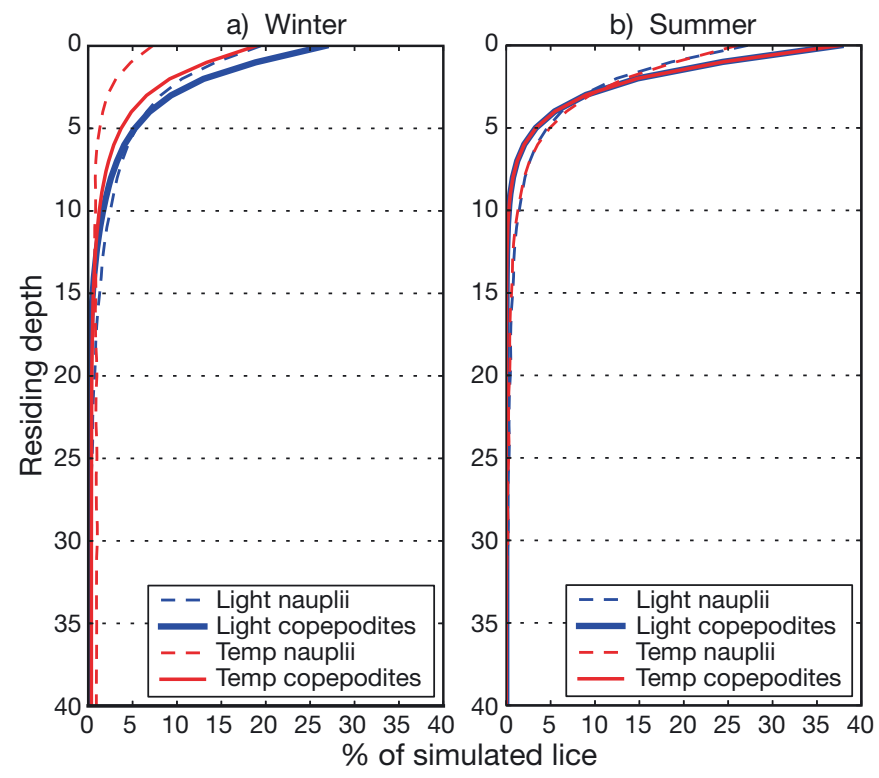

Fig. 10. Emergent vertical distribution of simulated Lepeophtheirus salmonis in the Hardangerfjord based on current fields from the model NorKyst800 in (a) winter and (b) summer. The values are integrated over time where the distributions are controlled by migration towards the surface when exposed to light (Light), while avoiding low-salinity water, or by vertical migration to achieve the highest ambient temperature (Temp) during the nauplii stages. All copepodites migrated towards the surface while avoiding low-salinity water

residing depth close to $100 \mathrm{~m}$ (Fig. 8). These salmon lice had a long trip back up to the surface once reaching the copepodite stage, which influenced the vertical distribution also during the copepodite stage (Figs. $9 \mathrm{~b} \& 10 \mathrm{a})$. This is simply a consequence of the assumption that lice nauplii use temperature as the only cue determining habitat selection.

During May, the temperature-controlled nauplii experienced stimuli triggering them to swim towards the surface on average $3 \%$ more (in $\mathrm{m} \mathrm{d}^{-1}$ ) than the light-controlled nauplii. But during the winter stratification in March, the light-controlled salmon lice swam longer distances upwards than the temperaturecontrolled ones. During this simulation, the differences were much larger and the light-controlled nauplii swam on average $95 \%$ longer per day than the temperature-controlled nauplii. Entering the copepodite stage, the temperature-controlled nauplii altered their positioning by swimming towards light. As they were deep down during the nauplii stage, they had a long way back towards the surface. The salmon lice migrating towards the light in both nauplii and copepodite stages swam an average of $10 \%$ longer upwards during all pelagic stages than the salmon lice swimming towards warm waters during the nauplii stages.

\section{Salmon lice stage duration}

The development of the simulated salmon lice from newly hatched to the infectious copepodite stage decreased from about $8 \mathrm{~d}$ in March to $6 \mathrm{~d}$ in May due to increasing temperatures. Assuming a constant mortality rate of $0.17 \mathrm{~d}^{-1}$, the survival chance was simply a function of development time, controlled by the salmon lice ambient temperature. The development time of the simulated salmon lice corresponds with a survival chance to infectious stage of $25 \%$ and $35 \%$ in March and May, respectively. During March, temperature was increasing with depth (Fig. 4), and by swimming down and increasing their ambient temperature, the salmon lice were able to shorten their development time by almost $1 \mathrm{~d}$. The decreased development time increased the survival chance from $23 \%$ for light-controlled nauplii to $28 \%$ for the temperature-controlled nauplii. During May, on the other hand, the warmest water was found at the surface (Fig. 4), and hence both light- and temperaturecontrolled behavioural cues resulted in upward swimming. As a result, the salmon lice with different behavioural responses all remained close to the surface and their development time was not affected much by vertical migration (Table 1).

\section{DISCUSSION}

Salmon lice are known to be responsive to environmental cues such as light and salinity (Bron et al. 1991, Heuch 1995, Heuch et al. 1995, Bricknell et al. 2006). Temperature dependency in development has also been documented (Johnson \& Albright 1991, Boxaspen \& Naess 2000, Stien et al. 2005). Using hydrodynamic models to calculate the dispersal of salmon lice, we need to decide the depth position of each individual particle, and a natural choice is to

Table 1. Simulated Lepeophtheirus salmonis. Development time to copepodite stage for the simulations 'Surf' (copepodites fixed at the surface), 'Light' (vertical migration controlled by light and salinity), and 'Temp' (temperaturecontrolled vertical migration), presented as mean number of days, with variance $\left(\sigma^{2}\right)$ shown in parentheses, for March and May in the $800 \mathrm{~m}$ resolution model, and for May in the $200 \mathrm{~m}$ resolution model

\begin{tabular}{|lccr|}
\hline & \multicolumn{3}{c|}{ Development time (d) } \\
\cline { 2 - 4 } & Surf & Light & \multicolumn{1}{c|}{ Temp } \\
\hline March 800 & $8.35(1.23)$ & $8.67(1.32)$ & $7.45(0.1)$ \\
May 800 & $6.2(0.5)$ & $6.1(0.5)$ & $6.1(0.5)$ \\
May 200 & $6.3(0.4)$ & $5.9(0.3)$ & $5.9(0.3)$ \\
\hline
\end{tabular}


make this dependent on environmental cues perceived by the lice. Here we have tried to integrate both observations from the lab on how lice respond to some cues and an experimental temperaturedependent response, and to model the consequences for dispersal in a fjord system.

There are a number of environmental factors that potentially influence the behaviour of copepods such as salmon lice. Simulations can be a useful tool to identify which behavioural responses affect the salmon lice transport, and hence identify which of the responses are essential to improve our knowledge about. If we succeed in this procedure, we have a powerful tool to identify infection pressures of farmed and wild fish for large areas applicable for management purposes.

In Expt 1 (fixed depths), we showed that the vertical positioning of the particles affects horizontal transport away from the source. Although repetitions of the experiment for a different period with a different current field would alter the distributions, we believe the differences between the vertical positions would remain.

Particles released at the outer position had a larger sensitivity to depth distribution than particles released at the inner position. This was a result of wind-driven currents close to the surface. At the inner release position, steep mountainsides force the wind along the fjord. Under the surface layer, the wind no longer dominates the driving forces of the current. Here, the dominating forces are tidal and pressure-driven currents that are directed along the fjord. In addition, the fjord is so narrow in the inner parts that the Coriolis effect only applies for time periods with a pronounced freshwater layer (Gill 1982). Together, this results in a total transporting current directed mainly in or out of the fjord, with a vertical shear in magnitude. No driving forces are directed across the fjord, and the current will be directed along the fjord at any depth. At the outer release position, the fjord is more closely connected to the open ocean through several sounds, and the landscape is relatively flat. This results in a more complex vertical current shear. In this area, the tidal and pressure-driven currents are directed along the fjord, but the baroclinic component is affected by the rotational Coriolis force. The surface layer is often dominated by wind-driven currents, and in the outer parts of the fjord, the wind can be directed in all directions, depending on the overlying air masses. Our simulations in Expt 1 showed a reduced horizontal distribution of particles fixed at the surface compared to deeper particles. These results are believed to represent real dispersion for near-surface material in open parts of fjords. However, the model implementation where particles directed onto land are held at their location may to some degree exaggerate this effect.

The finding that particles fixed at the surface are less dispersed was also evident in Expt 2 (behavioural cues). The dispersal area of particles fixed at the surface was $65-85 \%$ less than the particles having a vertical distribution controlled by environmental cues. Also, areas with the highest concentration of copepodites were the smallest for the particles fixed at the surface. Dispersal models of salmon lice often use currents from the surface layer alone to disperse the particles (Amundrud \& Murray 2009, Adams et al. 2012, Salama et al. 2013). In these cases, the surface layer is $4 \mathrm{~m}$ deep. Our model has a far better resolution close to the surface where the surface layer is between 0.3 and $0.6 \mathrm{~m}$, and the differences found in this study might not be transferrable to other dispersion models. Especially for wind-driven currents, the vertical gradient decays from the surface following a logarithmic profile (Ekman 1905), and using average values over a $4 \mathrm{~m}$ thick surface layer can be a misrepresentation of the overall dispersion pattern. Furthermore, in fjords and estuaries, the brackish surface layer usually is only 1-2 m thick, and an undersampling of this vertical gradient of especially salinity can have an unpredictable effect on the energy balance of the system (Asplin 1999).

In the ocean, salmon lice are always mixed by turbulent forces. They will therefore be collected only at the surface in very low turbulent systems even if they are continuously swimming towards the surface. The mixing forces will lead to a dynamic distribution of the salmon lice. A study by Penston et al. (2008) utilizing plankton trawls found salmon lice copepodites to be more abundant at the surface than at $5 \mathrm{~m}$ depth. However, the assumption that all salmon lice remain within a $0.3-0.6 \mathrm{~m}$ thick surface layer appears to be unrealistic. Dispersing all the salmon lice in the surface currents as shown in Expt 2 reduced the area affected by salmon lice, and transported a major fraction of the simulated salmon lice to different areas than in the dynamic distribution.

The vertically migrating salmon lice from the simulation 'Light' (Fig. 10) were given behavioural responses to light and salinity based on laboratory observations. The resulting vertical distribution agrees with the field observations of vertical salmon lice copepodite distributions from the field (Penston et al. 2008). Our model predicted an aggregation of salmon lice copepodites along shorelines. Field studies 
found the density of salmon lice nauplii to decrease with distance from salmon farms in a Scottish loch (Penston et al. 2008), while the copepodites were most dense along shorelines (McKibben \& Hay 2004, Penston et al. 2008). Our simulations of lightcontrolled salmon lice correspond well with these observations. The higher in the water column the simulated lice remained, the more pronounced the aggregation was along the shoreline.

During May, lice following light and those following temperature were triggered into upward swimming, and distributed close to the surface. Even if light-controlled nauplii showed more diurnal migration than the temperature-controlled ones, the horizontal transport was similar under the prevailing environmental gradients. This indicates that for these prevailing gradients, the diurnal migration of salmon lice was less important for the realistic simulation of horizontal dispersal. Amundrud \& Murray (2009) found little difference in the distribution between modelled salmon lice fixed in a surface layer $(0-4 \mathrm{~m}$ depth) and diurnally migrating between layers of 0-4 and 4-8 m depth. However, as the current shear close to the surface often is strong (Myksvoll et al. 2011, Asplin et al. 2014), and vertical migration patterns sometimes yield large dispersal effects (Fiksen et al. 2007, Vikebø et al. 2007), this behavioural response remains important to consider.

As the development time of the planktonic stages are dependent on temperature and the mortality is assumed to be constant at $0.17 \mathrm{~d}^{-1}$, survival of salmon lice to the infectious stage must increase with temperature. This is reflected in the model results, where the survival was 35\% in May against 25\% in March. The mortality rate used in our simulation was calculated by Stien et al. (2005) based on the work of Johnson \& Albright (1991). At $10^{\circ} \mathrm{C}$, Pert et al. (2012) found $57.3 \%$ of the salmon louse to survive to the copepodite stage. Assuming that the development to the copepodite stage at $10^{\circ} \mathrm{C}$ took $5 \mathrm{~d}$ (50 degreedays), this corresponds to a constant mortality of about $0.11 \mathrm{~d}^{-1}$. As these values are from laboratory experiments and do not include predation, which is probably the dominating source of mortality in nature, we need to interpret survival rates with caution here. But assuming mortality is constant in time and space, and assuming a temperature-dependent development time, then overall mortality of salmon lice copepodites must decrease with temperature. This will not only play a role between seasons as in our analysis, but will also result in greater survival of salmon lice to the infectious stage in the south than in the north due to the temperature differences.
As both temperature- and light-controlled salmon lice were found to have very similar vertical distribution in May during both nauplii and copepodite stages and hence experiencing the same temperatures, there was little difference in development time. But during March, the environmental gradients made the temperature-controlled nauplii swim deep into the fjord, avoiding the cold water close to the surface. The vertical migration of salmon lice during the nauplii stages decreased the development time to the infectious copepodite stage, and clearly the deep migration affected the horizontal dispersion of the simulated lice. As the vertical migration triggered by temperature gradients was found to result in less vertical swimming than the light-triggered migration during March, the mortality difference between the light and temperature simulations would increase if mortality were linked to swimming activity in the model.

In reality, mortality will be a function of several factors, such as activity and predator abundances. Some zooplankton respond to predators by flexible vertical migration behaviours (Ohman 1990, Bollens \& Frost 1991, Pearre 2003). Since salmon lice are a planktonic parasite with the need to find a host during the copepodite stage, it is unknown and perhaps unlikely that these responses are adaptive for infectious salmon lice, but it will need a cue to remain in the upper layers. Prior to the infectious stage, the salmon lice are non-feeding. During these stages, predator-avoidance behaviour might be stronger and they may be using other cues to guide depth positioning. The temperature-controlled nauplii in Expt 2 show that if differently motivated vertical responses are present, it will affect the horizontal distribution of lice from a source.

In conclusion, we need a better foundation for behavioural cues used by copepods and lice. Much effort has been made to obtain knowledge of the salmon lice's response to environmental factors. In laboratory experiments, salmon lice are often held under idealized conditions, exposed to controlled stimuli where the response is observed, but to transfer the result to a real case where it is exposed to turbulence, predators and other simultaneous stimuli is challenging. Observing salmon lice directly in nature may be more reliable, but provides limited information on the individual characteristics that the measurement reflects. Numerical models allow us to simulate and examine the effects of different assumptions about behaviour in a realistic setting. This way we can establish a more detailed and accurate understanding of how behavioural responses to environmental cues affect our ability to model distribution and dispersal of salmon lice. 


\section{LITERATURE CITED}

Adams T, Black K, MacIntyre C, MacIntyre I, Dean R (2012) Connectivity modelling and network analysis of sea lice infection in Loch Fyne, west coast of Scotland. Aquacult Environ Interact 3:51-63

Aksnes DL, Dupont N, Staby A, Fiksen Ø, Kaartvedt S, Aure $\mathrm{J}$ (2009) Coastal water darkening and implications for mesopelagic regime shifts in Norwegian fjords. Mar Ecol Prog Ser 387:39-49

Albretsen J, Sperrevik AK, Staalstrøm A, Sandvik AD, Vikebø F, Asplin L (2011) NorKyst-800 report no. 1: User manual and technical descriptions. IMR Res Rep Ser Fisken og Havet 2/2011. Institute of Marine Research, Bergen

Amundrud TL, Murray AG (2009) Modelling sea lice dispersion under varying environmental forcing in a Scottish sea loch. J Fish Dis 32:27-44

Asplin L (1999) Effects of insufficient vertical resolution in a 3D coastal ocean model. IMR Rep Ser Fisken og Havet, Vol 3. Institute of Marine Research, Bergen

Asplin L, Boxaspen K, Sandvik AD (2004) Modelled distribution of salmon lice in a Norwegian fjord. ICES CM, 2004/P:11

Asplin L, Boxaspen K, Sandvik AD (2011) Modeling the distribution and abundance of planktonic larval stages of Lepeophtheirus salmonis in Norway. In: Jones S, Beamish R (eds) Salmon lice: an integrated approach to understanding parasite abundance and distribution. John Wiley \& Sons, Oxford, p 31-50

Asplin L, Johnsen IA, Sandvik AD, Albretsen J, Sundfjord V, Aure J, Boxaspen KK (2014) Dispersion of salmon lice in the Hardangerfjord. Mar Biol Res 10:216-225

Bjørn PA, Finstad B, Kristoffersen R (2001) Salmon lice infection of wild sea trout and arctic char in marine and freshwaters: the effects of salmon farms. Aquacult Res 32: 947-962

> Bollens SM, Frost BW (1991) Diel vertical migration in zooplankton: rapid individual response to predators. J Plankton Res 13:1359-1365

Boxaspen K, Naess T (2000) Development of eggs and the planktonic stages of salmon lice (Lepeophtheirus salmonis) at low temperatures. Contrib Zool 69:51-55

Bricknell IR, Dalesman SJ, O'Shea B, Pert CC, Luntz AJM (2006) Effect of environmental salinity on sea lice Lepeophtheirus salmonis settlement success. Dis Aquat Org 71: 201-212

> Bron JE, Sommerville C, Jones M, Rae GH (1991) The settlement and attachment of early stages of the salmon louse, Lepeophtheirus salmonis (Copepoda, Caligidae) on the salmon host, Salmo salar. J Zool (Lond) 224:201-212

Bron JE, Sommerville C, Rae GH (1993) The functionalmorphology of the alimentary canal of larval stages of the parasitic copepod Lepeophtheirus salmonis. J Zool (Lond) 230:207-220

- Brooks KM, Stucchi DJ (2006) The effects of water temperature, salinity and currents on the survival and distribution of the infective copepodid stage of the salmon louse (Lepeophtheirus salmonis) originating on Atlantic salmon farms in the Broughton Archipelago of British Columbia, Canada (Brooks, 2005) - a response to the rebuttal of Krkošek et al. (2005a). Rev Fish Sci 14:13-23

Ekman VW (1905) On the influence of the earth's rotation on ocean currents. Ark Mat Astron Fys 2:1-53

Farmer DM, Freeland HJ (1983) The physical oceanography of fjords. Prog Oceanogr 12:147-219

> Fiksen $\varnothing$, Jørgensen C, Kristiansen T, Vikebø F, Huse G (2007) Linking behavioural ecology and oceanography: larval behaviour determines growth, mortality and dispersal. Mar Ecol Prog Ser 347:195-205

Finstad B, Bjørn PA, Grimnes A, Hvidsten NA (2000) Laboratory and field investigations of salmon lice [Lepeophtheirus salmonis (Krøyer)] infestation on Atlantic salmon (Salmo salar L.) post-smolts. Aquacult Res 31:795-803

> Flamarique IN, Browman HI, Belanger M, Boxaspen K (2000) Ontogenetic changes in visual sensitivity of the parasitic salmon louse Lepeophtheirus salmonis. J Exp Biol 203: 1649-1657

Gill AE (1982) Atmosphere-ocean dynamics, Vol 30. Academic Press, London

Gillibrand PA, Willis KJ (2007) Dispersal of sea louse larvae from salmon farms: modelling the influence of environmental conditions and larval behaviour. Aquat Biol 1: 63-75

$>$ Heuch PA (1995) Experimental evidence for aggregation of salmon louse copepodids (Lepeophtheirus salmonis) in step salinity gradients. J Mar Biol Assoc UK 75:927-939

- Heuch PA, Karlsen HE (1997) Detection of infrasonic water oscillations by copepodids of Lepeophtheirus salmonis (Copepoda: Caligida). J Plankton Res 19:735-747

Heuch PA, Parsons A, Boxaspen K (1995) Diel vertical migration: a possible host-finding mechanism in salmon louse (Lepeophtheirus salmonis) copepodids? Can J Fish Aquat Sci 52:681-689

$>$ Heuch PA, Bjorn PA, Finstad B, Asplin L, Holst JC (2009) Salmon lice infection of farmed and wild salmonids in Norway: an overview. Integr Comp Biol 49(Suppl 1):e74, doi:10.1093/icb/icp002

Johnson SC, Albright LJ (1991) Development, growth, and survival of Lepeophtheirus salmonis (Copepoda, Caligidae) under laboratory conditions. J Mar Biol Assoc UK 71:425-436

Kiørboe T (2008) A mechanistic approach to plankton ecology. Princeton University Press, Princeton, NJ

- Kiørboe T, Andersen A, Langlois VJ, Jakobsen HH (2010) Unsteady motion: escape jumps in planktonic copepods, their kinematics and energetics. J R Soc Interface 7: 1591-1602

McGurk MD (1986) Natural mortality of marine pelagic fish eggs and larvae: role of spatial patchiness. Mar Ecol Prog Ser 34:227-242

> McKibben MA, Hay DW (2004) Distributions of planktonic sea lice larvae Lepeophtheirus salmonis in the inter-tidal zone in Loch Torridon, Western Scotland in relation to salmon farm production cycles. Aquacult Res 35:742-750

> Miller SH, Morgan SG (2013) Phenotypic plasticity in larval swimming behavior in estuarine and coastal crab populations. J Exp Mar Biol Ecol 449:45-50

Mo TA, Heuch PA (1998) Occurrence of Lepeophtheirus salmonis (Copepoda: Caligidae) on sea trout (Salmo trutta) in the inner Oslo Fjord, south-eastern Norway. ICES J Mar Sci 55:176-180

> Murray AG, Gillibrand PA (2006) Modelling salmon lice dispersal in Loch Torridon, Scotland. Mar Pollut Bull 53: 128-135

- Myksvoll MS, Sundby S, Ådlandsvik B, Vikebø FB (2011) Retention of coastal cod eggs in a fjord caused by interactions between egg buoyancy and circulation pattern. Mar Coast Fish 3:279-294

Ohman MD (1990) The demographic benefits of diel vertical 
migration by zooplankton. Ecol Monogr 60:257-281

Pearre S (2003) Eat and run? The hunger/satiation hypothesis in vertical migration: history, evidence and consequences. Biol Rev Camb Philos Soc 78:1-79

Penston MJ, Millar CP, Zuur A, Davies IM (2008) Spatial and temporal distribution of Lepeophtheirus salmonis (Krøyer) larvae in a sea loch containing Atlantic salmon, Salmo salar L., farms on the north-west coast of Scotland. J Fish Dis 31:361-371

> Pert CC, Mordue AJ, O'Shea B, Bricknell IR (2012) The settlement and reproductive success of Lepeophtheirus salmonis (Krøyer 1837; Copepoda: Caligidae) on atypical hosts. Aquacult Res 43:799-805

Peterson I, Wroblewski JS (1984) Mortality rate of fishes in the pelagic ecosystem. Can J Fish Aquat Sci 41: 1117-1120

Petterson LE (2008) Beregning av totalavløp til hardangerfjorden. Oppdragsrapport A:27. Norges vassdrags-og energidirektorat, Oslo (in Norwegian)

Pike AW, Wadsworth SL (1999) Sealice on salmonids: their biology and control. Adv Parasitol 44:233-337

Salama NK, Collins CM, Fraser JG, Dunn J, Pert CC, Murray $A G$, Rabe $B$ (2013) Development and assessment of a biophysical dispersal model for sea lice. J Fish Dis 36: 323-337

Shchepetkin AF, McWilliams JC (2005) The regional oceanic modeling system (ROMS): a split-explicit, freesurface, topography-following-coordinate oceanic model. Ocean Model 9:347-404

Skartveit A, Olseth JA (1988) Varighetstabeller for timevis belysning mot 5 flater på 16 norske stasjoner. Meteoro-

Editorial responsibility: Bengt Finstad,

Trondheim, Norway logical Report Series 7. Unversity of Bergen, Bergen (in Norwegian)

Stien A, Bjørn PA, Heuch PA, Elston DA (2005) Population dynamics of salmon lice Lepeophtheirus salmonis on Atlantic salmon and sea trout. Mar Ecol Prog Ser 290: 263-275

Stigebrandt A (2012) Hydrodynamics and circulation of fjords. In: Bengtsson L, Herschy RW, Fairbridge RW (eds) Encyclopedia of lakes and reservoirs. Springer, Dordrecht, p 327-344

Stucchi DJ, Guo M, Foreman MG, Czajko P, Galbraith M, Mackas DL, Gillibrand PA (2011) Modeling sea lice production and concentrations in the Broughton Archipelago, British Columbia. In: Jones S, Beamish R (eds) Salmon lice: an integrated approach to understanding parasite abundance and distribution. John Wiley \& Sons, Oxford, p 117-150

Sundby S (1983) A one-dimensional model for the vertical distribution of pelagic fish eggs in the mixed layer. DeepSea Res A 30:645-661

Tapia FJ, Pineda J (2007) Stage-specific distribution of barnacle larvae in nearshore waters: potential for limited dispersal and high mortality rates. Mar Ecol Prog Ser 342:177-190

Taranger GL, Asplin L, Aure J Bannister R and others (2013) Risikovurdering norsk fiskeoppdrett 2012. Report No. 0802-0620: 14-40. Havforskningsinstituttet, Bergen (in Norwegian)

Vikebø F, Jørgensen C, Kristiansen T, Fiksen Ø (2007) Drift, growth, and survival of larval Northeast Arctic cod with simple rules of behaviour. Mar Ecol Prog Ser 347:207-219

Submitted: January 2, 2014; Accepted: March 18, 2014

Proofs received from author(s): May 26, 2014 